Paper prepared for presentation to the $28^{\text {th }}$ Annual TPRC

\title{
Knowledge Networks, the Internet, and Development
}

\author{
Peter Cukor and Lee W. McKnight \\ Edward R. Murrow Center \\ Fletcher School of Law and Diplomacy \\ Tufts University
}


Knowledge Networks, the Internet, and Development

Peter Cukor and Lee W. McKnight

\begin{abstract}
Information and Communications Technologies (ICTs) are playing a significant role in economic, political and cultural development. The relationship between technologies supporting information processing and distribution, and the application of that knowledge for development purposes has only recently come into focus. The discovery, publication and application of new knowledge, the dissemination of information concerning best practices and the exchange of views and opinions are now considered essential elements of development work. These functions it is now increasingly recognized, are effectively facilitated by ICTs. In the area of economic development ICTs can create new jobs, new industry and service sector opportunities and a more educated work force. They make possible the cross-border flow of information, promote international trade, particularly high technology, bits rather than atoms, type trade and help to attract foreign direct investment. ICTs can also contribute to political development by fostering good governance and streamlining bureaucratic procedures through intra-governmental networking. The creative use of ICTs, particularly the Internet, in the areas of health care, education, environmental protection and in other developmentally important fields can substantially contribute to the advancement of developing societies.

This paper identifies the causes and consequences for these trends and considers their implications for the further development of knowledge networks for development of the global Internet economy.
\end{abstract}

Corresponding author:

peter.cukor@gte.com 


\section{Introduction}

The rapidly increasing global economic significance of ICTs - Information and Communication Technologies - is clearly demonstrated by the example of the software industry. Programmers in less developed countries, India, Russia and its former Eastern European allies, Israel, can work as regular employees of multinational corporations without leaving their country or even their home. Clearly testifying to the "death of distance", these programmers write computer code on their own computer and communicate with their employers via the Internet or a proprietary Intranet. ${ }^{1}$ They are able to participate in the Information Economy not because they live in an industrialized country or because they have access to the latest high technology but because they have an appropriate education. This example highlights many of the major issues of the information age as it relates to the developing world.

The Internet is particularly well suited to facilitate and support a new and increasingly more popular paradigm in development, the so called Knowledge Networks. These networks bring together institutions and people from all parts of the world and from all strata of society. Knowledge Networks in the arena of development are dedicated to the discovery of new knowledge and its application for the advancement of developing nations and regions. The key their popularity and initial success is the realization that all participants, both Northern and Southern people and institutions, can and should learn from each other and should acquire the technology and the capacity for knowledge creation, aggregation and exchange

As has been shown by our example above, Information and Communication Technologies (ICTs) play a significant role in economic, political and cultural development. The discovery, publication and application of new knowledge, the dissemination of information concerning best practices and the exchange of views and opinions are essential elements of development work which are effectively facilitated by ICTs. In the area of economic development, ICTs can create new jobs, new industry and service sector opportunities and a more educated work force. They make possible the cross-border flow of information, promote international trade, particularly high technology. Trade in bits rather than atoms ${ }^{2}$ is the type of trade which helps to attract foreign direct investment. ICTs can also contribute to political development by fostering good governance and streamlining bureaucratic procedures through intra-governmental networking. The creative use of ICTs, particularly the Internet, in the areas of health care, education, environmental protection and in other important fields can substantially contribute to the advancement of developing societies.

This article analyzes the role of information and communication technologies, and in particular the Internet, in enabling the creation and application of knowledge networks. The article draws examples from wealthier nations, but focuses on the implications of

\footnotetext{
${ }^{1}$ Frances Cairncross, The Death of Distance, Harvard Business School Press, 1998.

${ }^{2}$ Nicholas Negroponte, Being Digital, Knopf, 1995
} 
these technological trends for the socio-economic development in re-emerging and developing nations of Africa, Asia, Eastern Europe, and Latin America. However, the same issues and approaches identified in this article are also relevant and possibly applicable across the 'digital divides' which can be found across and within regions in the wealthiest societies. In this article, the concept knowledge networks and their increasingly significant role in socio-economic development is highlighted and the term, knowledge networks, is defined more precisely. Scholarship from academics and development professionals is then reviewed to show the importance of ICTs, the Internet and Knowledge Networks in the development work. Next, the article analyzes requirements for the successful application of ICTs in the developing world and concludes that the primary critical issue in this regard is the availability of Internet access (equipment, connectivity and skills) by the general population.

\section{Defining Knowledge Networks}

The Internet is particularly well suited to facilitate and support a new and increasingly more popular approach to development, the creation and utilization of so called Knowledge Networks. These networks bring together institutions and people, possibly from all parts of the world and from all strata of society. Knowledge Networks in the arena of development are dedicated to the discovery of new knowledge and its application for the advancement of developing nations and regions. The key to their popularity and initial success is the realization that all participants, people and institutions in the North, South, East and West, can and should learn from each other and should acquire the technology and the capacity for knowledge creation, aggregation and exchange. ${ }^{3}$

In our fast moving, dynamically changing information society it is difficult to define a complex and multifaceted concept like Knowledge Networks precisely because the participants constantly shape and extend the activities of these networks in response to real needs and challenges. Howard Clark defined communications networks as (interaction) "of people, dispersed over geographically separate sites, (equipped) with appropriate communications technology". 4 In defining Knowledge Networks he differentiated four types of entities: 1. informal, 2. information access, 3. open and 4. development networks. Informal networks represent casual, ad-hoc interactions, they are without structure and the knowledge they create often does not get disseminated.

Information access networks are exemplified by university or government libraries; they are the repositories of existing knowledge but according to Clark they create no new knowledge. Open networks exist to conduct research in science, technology or on policy related issues and are not very much concerned about the practical applications of their research results. They have a well defined structure and governance and disseminate their finding through publications. Participation in open networks is by invitation based on merit and past performance. Development networks focus on a well defined theme around which their various projects converge. These networks exist not only to create

\footnotetext{
${ }^{3}$ Knowledge Networks - IISDnet, http://iisd1.iisd.ca/k.networks.htm

${ }^{4}$ Howard C. Clark, Formal Knowledge Networks - A Study of the Canadian Experience, International Institute for Sustainable Development, 1998
} 
new knowledge but to accelerate its application. Development networks are highly structured, have strong governance and participation is by invitation based on merit. Besides exhibiting the above discussed characteristics, Knowledge Networks, according to Clark, also have to possess certain other attributes. They must be optimized for maximum rate of knowledge creation and sharing so as to lessen rather than enlarge the gap between developed and developing nations. They certainly must create knowledge faster than other approaches can. A Knowledge Network must also be cost effective and efficient and must provide direct and tangible benefits to all its participants in order to sustain itself; this usually means financial support for the academic participants and applicable research results for the industrial and government sponsors. And very importantly, a Knowledge Network should involve several sectors of the economy, such as industry, finance, universities and government to synthesize diverse point of views.

Clark stated that of these four types of networks only the last two, the open and the development networks, can be classified as formal Knowledge Networks. It should be noted, however, that some of his reservations about informal and information access networks have been since positively addressed by the Internet. In today's environment the often hidden knowledge discoveries of informal networks are readily yet informally publishable using web servers and electronic mail. An interesting exchange of ideas between two individuals can be transformed to text and disseminated to hundreds of interested people without difficulty. In the case of information access networks, modern Digital Libraries provide more than access to information. They allow data mining, that is to say, the processing of information in such manner that new correlations and new knowledge may be discovered within the existing information. These discoveries, in turn, can be readily disseminated to interested individuals in a Knowledge Network. Internet based communications and information processing technologies have upgraded the role of informal and information access networks and allowed them to approach the characteristics of formal Knowledge Networks.

More recently, the meaning of the term Knowledge Network has further broadened to encompass any type of network operation aimed at the management, organization and sharing of knowledge. Thus corporations and government, non-profit or civic organizations of all kind designate the people and computers networked for the purpose of accumulation, organization, management and sharing of a specific body of knowledge as a knowledge network. Researchers at SUNY, Albany, for instance, define Knowledge Networks in conjunction with their investigation of "Knowledge Networks in the Public Sector" in a very broad manner: " a combination of inter-organizational relationships, policies, information content, work processes and technology tools and architectures brought together to achieve collectively defined purposes." 5

At any rate, no matter how defined, Knowledge Networks, in general, and development oriented Knowledge Networks in particular, are expected, by their purpose and nature, to shift organizational culture towards collaborative activities within and among institutions. This often means multidisciplinary, multisectoral and multinational participation and

\footnotetext{
${ }^{5}$ Sharon Dawes et al. Knowledge Networking in the Public Sector, http://www.nsf.gov/cgibin/showaward?award+9979839
} 
non-adversary relationship with government and industrial sponsors. Development related Knowledge Networks must also operate within the spirit of sustainable development, that is to say, they must consider factors of economic development and harmonize them with environmental protection, social development and the standard of living and well being of the population involved. ${ }^{4}$ It is axiomatic that development related Knowledge Networks are most effective when they transcend national boundaries and involve participants from both developing and developed nations. This requires the availability of efficient and compatible communications networks for all participants. The Internet has served as such an all purpose communications network admirably well. In addition to facilitating ready interactions among participants, the Internet also became an integral part of Knowledge Networks by serving as the primary tool of knowledge acquisition, sharing and application. In the balance of this paper we will examine the importance of the Internet in the functioning of development related Knowledge Networks.

\section{Knowledge Networks and the Internet}

The significance of the Internet as a powerful tool for sharing knowledge was emphasized by Joseph Stiglitz, former chief economist of the World Bank, at the First Development Network Conference which took place in Bonn, Germany in December of 1999. ${ }^{6}$ He pointed out that in development work this immense network of networks presents both risks and opportunities. On the risk side, the growth of the Internet has been much greater in the United States and in other developed countries than in the developing world. This may make the Internet a tool of enhancing rather than narrowing the gap between developed and developing nations. This factor, however, is counterbalanced by the opportunities provided by the greater and more readily accessible knowledge pool the Internet makes available to those with access to it. "Today, a child anywhere in the world who has access to the Internet has a modern Alexandria Library at her fingertips." Indeed, according to a 1999 report, at that time, there were 800 million webpages representing 6 terrabytes of data over 3 million servers. ${ }^{7}$

Stiglitz advocates as his main thesis the approach to "Scan Globally, Reinvent Locally". In other words, the global knowledge acquired from the existing repositories, such as major libraries, databases and other sources of knowledge made available on the Internet, must be internalized, rediscovered and translated to local conditions if it is to be usefully applied in development. An example of this principle in action was described by Robert Chassell, a co-founder of the Free Software Foundation, at the recent Global Knowledge Conference in.$^{8}$ He explained how he ran simplified free software, or more accurately, open source applications on old IBM 486 machines which are available at low prices in

\footnotetext{
${ }^{6}$ Joseph Stiglitz, Scan Globally, Reinvent Locally: Knowledge Infrastructure and the Localization of Knowledge, First Development Network Conference, Bonn, Germany, December 1999, http://orion.forumone.com/gdnet/files.fcgi/226_GDNfinal.PDF

${ }^{7}$ Steven Lawrence and Lee Giles Accessibility and Distribution of Information on the Web 1999 http://wwwmetrics.com/

${ }^{8}$ Robert J. Chassel, Shaping Collaborative ICT Development and Initiatives for Global Prosperity, March 2000. http://www.globalknowledge.org.my/Track\%205\%20(Chassell).doc
} 
the developing world. By translating the software and hardware requirements to a locally affordable level, Chassell has made global knowledge accessible locally.

Stiglitz's "Scan Globally, Reinvent Locally" thesis may explain why the Internet is a particularly useful network in the development arena; even more useful than the traditional telephone or broadcast networks One might argue that the Internet itself is predicated on the same "global and local" principle. In an enlightening paper Isenberg compares the telephone network and the Internet ${ }^{9}$. The telephone network is a hierarchical entity, subject to rigid, automated internal controls. Basically the telephone network is optimized for one application: the transmission of voice (data is transmitted as voice) over real or virtual circuit paths. To introduce any new service, approval must be obtained from the telephone company which must also do the implementation of the proposed new service. The user has no input into network planning or service creation. A similar situation exists with broadcast networks: there is little or no direct user input into programming. By contrast, the Internet is an essentially uncontrolled network, void of central authority. To be sure, the fundamental technologies of the Internet, packet switching, TCP/IP software and client server architecture, are the same globally. The various network elements, however, are configured by the users according to their needs and desires and not by a central controlling authority. Perhaps most importantly, the Internet is capable of running many different applications such as electronic mail, filetransfer, the World Wide Web, Internet Telephony, Internet Video, MP3 music (audio streaming), MPEG4 video (video streaming) conferencing, multicasting, and interactive media services and all these drastically different applications are created and installed locally by the users without any involvement of the (non-existent) controlling authority. (For the sake of completeness it should be mentioned that, at least at this point, the rigid control of the telephone network results in high quality, reliable, albeit expensive and limited service; while the total lack of controls over the Internet yields essentially free and application rich but spotty quality service based on "best effort".) The global technology of the Internet and the local innovations and contents created on it are mirroring the global - local principle of development related knowledge acquisition and application. Consequently, the Internet, as the embodiment of the "global - local" principle, may be used by any country or region to collect global knowledge and translate it to local conditions. It is up to the users in the developing countries to create applications capable of carrying out the task of localization in a fashion optimized to their needs.

\section{Internet Access}

The importance of the ICTs has been fully recognized by the development community for some time. In 1980 the UNESCO General Conference initiated the international Programme for Development of Communications. ${ }^{10}$ In 1982, the International Telecommunications Unions's Plenipotentiary Conference established an independent commission to study telecommunications development. The Maitland Commission in its "Missing Link" report recommended high priority, large scale investment in

\footnotetext{
${ }^{9}$ David Isenberg and Francois Menard, Netheads vs. Bellheads, http://www.tmdenton.com/netheads.htm

${ }^{10} \mathrm{http}: / /$ www.unesco.org/opi/eng/unescopress/98-58e.htm
} 
telecommunications. ${ }^{11}$ Indeed there is a "digital rush" in the developing world, a feeling of urgency and fear of being left out of the Information Economy. Many believe, among them Nicholas Negroponte, Director of the MIT Media Lab., that the developing world can progress by skipping certain stages of industrial development and leapfrogging into the Information Economy. ${ }^{12}$ The validity of this theory is yet to be proven. There is no doubt, however, that ICTs, if properly adopted and implemented, can bring economic and cultural opportunities to developing countries. Education facilities may be greatly improved through distance learning and Internet access. Health care may be delivered to isolated and underserved communities. Industrial production may become more competitive by taking on a smaller scale, distributed version which would also reduce the pollution of the environment. This optimistic assessment of the role of ICTs in development was summarized by U.S. Vice President Al Gore at the ITU conference in Buenos Aires, Argentina in 1994 when he stated that the creation of the GII (which for all practical purposes is the global Internet) "is an essential prerequisite to sustainable development for all members of the human family".

A much more restrained assessment of the role of ICTs in the developing world has been given in the writings of Paula Uiomen of the UN Research Institute for Social Development. ${ }^{13}$ She argues that the success of the Internet should not be measured by the number of people connected to it, but by the extent its implementation improves the standard of living and well being of the people in the developing world. The issues she raises include the danger of the Internet accelerating the stratification of society to an 'information have' minority elite and an information have-not majority which does not have the resources and skills to utilize the technology. The funds needed to create a viable telecommunications infrastructure, the personal resources required to acquire a pc, the funds required to raise the low literacy level of the population indicate the enormous level of investment needed to realize the promise of the Information Economy. The only way the sacrifices of the population in the already debt-burdened developing countries will be worthwhile if they result in socially beneficial applications, such as health care, education, greater participation in the political process and in the simplification of Internet access through community based facilities (telecenters) and more locally acceptable technologies (translation software, less virtual interfaces) ${ }^{14}$.

In order to maximize the effectiveness of the Internet in development work, the ability to access it must be readily available to researchers and to the population at large in developing countries. In these areas of the world Internet access is closely related to

\footnotetext{
${ }^{11}$ INTER-AGENCY PROJECT ON UNIVERSAL ACCESS http://www.itu.int/acc/rtc/acctref/acctref.htm

${ }^{12}$ Nicholas Negroponte, THE THIRD SHALL BE FIRST The NET leverages latecomers in the developing world. http://www.media.mit.edu/people/nicholas/Wired/WIRED6-01.html

${ }^{13}$ Paula Uimonen, Internet as a Tool for Social Development, Annual Conference of the internet Society, INET 97, Kuala Lampur, June 1997

${ }^{14}$ An excellent example of these new ICT-focused local development projects is the LINCOS project. This project, developed in part at the MIT Media Lab, drops a sea freight container filled with computers, communication links, and specialized technologies for applications such as telemedicine or distance education, anywhere in a developing nation. The centers can be solar-powered, run off diesel generators, or connected to the local electrical grid.
} 
teledensity (number of phones per 1000 population) because access is often established through dial-up or increasingly with wireless or mobile, phone lines. Yet, Internet and telephone network considerations are not interchangeable because satellite and digital line (ISDN, T1, DSL) connections are also playing a role especially at the institutional, rather than individual user, level. Fixed wire network related teledensity is not increasing rapidly in many developing countries because of the preference for cheaper and more readily installed wireless networks. These, however, can also provide access to the Internet. In general, the beginnings of a diverse infrastructure for Internet access are sprouting in developing countries but access availability is still low, especially outside of large cities.

The 'Access Working Group' of the Global Knowledge Partnership made six recommendations aimed at the eventual creation of universal access to the Internet which would include even the poorest communities (rural populations) and the most disadvantaged groups (women, handicapped) of the world. ${ }^{15}$ The list of recommendations is as follows:

1. Evaluation of the Scope and Nature of the Access Challenge

2. Proper Targeting of public and Private Investment

3. Strategy, Policy and Regulation to Foster Innovation and Information Flow

4. Universal Access, Poverty Reduction and Sustainable Development

5. Human Resources and Capacity Building

6. Supporting Diversity of Global Information Flows

The first policy recommendation puts forth the need for an inventory of ongoing efforts in access improvement and the conducting of serious studies of the local needs related to access in developing countries. Only after these preliminary investigations are completed should plans be formulated for appropriate policies of access improvement. The second recommendation calls for the harmonization and targeting of public and private investment in access creation. The private sector may benefit from many opportunities in developing countries such as e-commerce based marketing, the development of local Internet applications and the enhancement of the existing network, which warrant private sector investment in local access creation. The third policy recommendation concerns strategy and regulation. It calls on the international community to assist developing countries in joining the information economy by convincing local policy makers to treat Internet access as a priority and to discontinue the control of publicly available information. Particularly important is diverse participation in standards making bodies and other ICT governance for a because the decisions of these organizations will determine the shape of access to the Internet in the future. The fourth recommendation asks for public sector intervention on access issues related to universal access, poverty reduction and sustainable development. The fifth policy recommendation discusses education and training. It proposes that the international community focuses on the training of key sectors of human resources such as teachers, media and NGOs which may be the important facilitators of Internet access. Finally, the sixth recommendation

\footnotetext{
${ }^{15}$ Recommendation of the Access Working Group of the Global Knowledge Partnership, February 2000 for the March 2000 Kuala Lumpur Global Knowledge Conference. http://www.globalknowledge.org/actionsummitprogram.html
} 
emphasizes the need to access not only knowledge available to the developed world but also knowledge appropriate and important for developing countries such as helping local farmers to improve their practices or aid citizens to participate in the work of their government successfully. Implementing these recommendations in a pragmatic manner is likely to remove many of the existing barriers to Internet access on the part of poor and disadvantaged societal segments of the developing world.

There are many projects aimed at creating and enhancing Internet access in the developing world. Evidence is beginning to accumulate that they are starting to bear fruit. In 1998 the Global Development Network surveyed all known development research institutions in developing countries concerning their connectivity to information resources. It found high connectivity and strong demand for on-line services to facilitate the creation and sharing of knowledge about development. ${ }^{16}$ The survey population represented employees of NGOs, think-tanks, independent and government research institutions and university departments. A full $94 \%$ of the survey respondents stated that their organization had access to both electronic mail and the World Wide Web. About $40 \%$ of them reported that more than half of their staff uses the Web regularly. There was particularly high value attached to access to searchable on-line archives of research papers. Interestingly, preferences for electronic services differ little across geographic regions, indicating large economies of scale in the use of electronic products. The preference for face to face contact, however, is still strong. When asked to identify most valuable job activities, survey respondents opted for choices associated with high marginal costs such as meeting attendance. When confronted with the reality of their department having to pay for these activities, preference was shifted to low marginal cost associated electronic data gathering. Management clearly needs to balance the more satisfying and more expensive personal contacts with the more efficient but perhaps much less satisfying electronic connectivity.

The utilization of readily available Internet access among development researchers was demonstrated by Darren Saywell an English researcher involved in water engineering and development issues. ${ }^{17}$. Saywell reported on three years of electronic mail conferencing experience by members of the Water Think Tank concerning water supply and sanitation related issues. He found that regular participation was motivated by rapid information exchange, wider access to experts and specialists, shared experience, relative low cost and automatic record creations and dissemination. The primary lesson learned from the experiment is that electronic mail conferencing is cost effective and efficient but successful implementation requires considerable preparation and discipline.

The above described Global Development Network survey of development researchers indicates that over $90 \%$ of them had both email and web connection by 1988 . Should this data be reliable and genuine, and there is no reason to believe that it is not, then one may conclude that Internet access among development researchers is no longer a major problem. The availability of access by the general population of most developing

\footnotetext{
${ }^{16}$ The Global Development Network Survey Results. http://www.gdnet.org/survey3.htm

${ }^{17}$ Darren Saywell, Electronic Conferencing and On-line Dialog for Development Purposes http://www.gdnet.org/bonn99/confpapers.f1ml
} 
countries, however, is still very limited. This is a major problem in development work. The lack of Internet access prevents the populous from being well informed about political and economic news and prevents the people from availing themselves to the benefits of distance education, telemedicine and similar services. In addition, economic development is also hampered because besides being a tool of knowledge acquisition and sharing, the Internet is also important in businesses development due to its ability to provide nation-wide, regional and world wide exposure to even small businesses at a reasonable cost. Reasonable by the standards of advanced nations, that is - still beyond the means of most citizens of developing countries. It appears that in the current circumstances wide spread access to the Internet is becoming a prerequisite to successful development work.

The many ongoing efforts, i.e. private sector and government partnerships for access creation, telecenters and other community based solutions are making a slow dent into the access problem. Indeed, the strongest rate of growth of the Internet exists in developing countries. ${ }^{18}$ There is, however, a long way to go as yet. In January of 1999 there were nearly 34 million Internet host computers in North America but only about 300 thousand in Africa. ${ }^{19}$ In many developing countries, Internet access and phone connections are billed on time and distance sensitive basis as opposed to flat usage fees. This, coupled with the relatively low per capita income in these countries inhibits Internet usage. Other factors negatively influencing Internet demand are scarcity of computers and telephone lines, not being able to use English, the currently predominant language of the Internet, and generally low education and skill levels. In a paper by Nabil Salah Mahmoud of the Murrow Center at the Fletcher School at Tufts University, a mathematical model for Internet access demand was developed. Using the dependent variable of "number of Internet users per 1000 population" he found that the most significant independent variables were teledensity (number of phone lines per 1000 people), computer penetration ( number of computers per 1000 people), adult literacy rate and real GDP per capita. ${ }^{20}$ The data used in constructing the model was obtained from UNDP's 1998 human development report. ${ }^{21}$ The model has shown that while teledensity, computer penetration and income levels have a small to moderate impact on Internet demand, the skill level and education of the population plays an overwhelming important role in determining Internet demand. Governments interested in fostering increased demand for Internet usage, clearly should invest in increasing the literacy level of their population.

The access problem is particularly acute in poor rural areas where not only computers and phone connections but even electricity may not be available. The currently emerging Third Generation Wireless (3G) technology for advanced mobile services may eventually supply some of the answers to the needs of these poor and underserved communities. The 3G technology will not use personal computers to access the Internet, but will rely on display screen equipped cellular telephones or palm computers instead. In addition, these Internet appliances will utilize batteries and cellular networks and thus will not require

\footnotetext{
${ }^{18}$ Global Internet Statistics, http://www.glreach.com/globstats/index.php3

${ }^{19}$ Jean Camp, Trust and Risk in Internet Commerce, MIT Press, Cambridge, MA, 2000

${ }^{20}$ Nabil Salah Mahmoud, Determinants of Internet Accesss Demand in Developing Economies, in press.

${ }^{21}$ http://www.undp.org/hdro/98/htm
} 
hard wire connections to the electric utility and the telephone networks. Many of these appliances will be highly specialized, performing preprogrammed steps at the push of a button, thus lowering the demands on the skill level of the user. In other words, the $3 \mathrm{G}$ technologies will liberate the users from the challenge of having to know how to operate a pc and will provide it with unprecedented independence and mobility. These Internet appliances will penetrate the market of the developed world. However, based on historical patterns in ICTs, prices should fall rapidly and they will become affordable in the developing world also. In fact, advanced mobile services will be available in some middle-income, developing nations, before all higher income countries have such services available. For example, services may be available in parts of Brazil before they are available in the U.S. This process is likely to be rapid because the developing world is being perceived as a significant market for e-commerce by the developed countries. The giant potential markets of China, India, and Indonesia are irresistible targets for ecommerce businesses. The demographic trend of population expansion in the developing world and population decrease in the developed world has highlighted the growing importance of the developing countries as consumer markets. It is likely that $3 \mathrm{G}$ will revolutionize Internet access much the same way as the transistor radio revolutionized access to radio broadcasts in the late 60's and early 70's. The social, political and economic impact of the transistor radio have been immense and similar impact is anticipated from the eventual ready availability of wireless Internet access in poor nations. The developing world will be able to harness the unique power derived from the ready availability of information.

Both the nature of information and the structure of the Internet foster knowledge sharing and communications. The value of material goods decline through usage. Row material deposits become less valuable upon depletion through mining. The value of finished products is determined by the cost of their duplication and they lose their value through wear and tear caused by repeated usage. Information is quite different. It is easy and inexpensive to duplicate and its value is not diminished but often increased by usage. The more information is disseminated and the more it is used the more valuable it is. Thomas Jefferson compared knowledge (information) to light. ${ }^{22}$ One can light a taper from a candle and spread its light further without diminishing the light of the original candle. And so it is with information dissemination.

Information is also empowering. Those who possess it have a clearer understanding of the issues and are more likely to be masters of their own destiny and able to accomplish their goals than those who do not. The Internet because of its open structure, standardized technology, uncontrolled and uncensored contents is a unique and ubiquitous tool of knowledge and information sharing. Today, essentially all of the published scientific and technical literature is available on the Internet. Works in progress, currently pursued research and even contemplated ideas are also often placed on Internet servers. Nearly all companies, schools and organizations have websites where they provide detailed descriptions of their objectives, existing and emerging products or activities and future plans. All this knowledge is readily available to anyone with access to a networked pc.

${ }^{22}$ Thomas Jefferson, No Patent on Ideas, 1813 in Writings, Library of America, New York 
At the same time, proprietary information, knowledge not universally shared but disseminated in a limited fashion, can give a significant economic and political advantage to those who possess it. Consider the knowledge contents of the confidential Intranets of companies and organizations where, using Internet-Protocol technology, the firm's employees and affiliates freely exchange results, plans and status reports. The Internet and the Intranets form an immense pool of information which together with the accompanying tools of communications (email, internet telephony) are the basis of the so called Information Economy. The constantly ongoing information exchange among networked knowledge workers, business and technology managers, scientists and engineers, government and organizational bureaucrats have greatly improved productivity, accelerated the product development cycle, revolutionized marketing and spurred innovation and entrepreneurship not only in developed countries but, admittedly to a lesser extent, in the developing world too.

\section{From Knowledge Networks to Knowledge Economy Alliances}

A key characteristic of the Knowledge Economy is the multiple and far ranging partnerships and alliances among its diverse participants. This is antithetical to the traditional industrial (or object) economy which was characterized by the high levels of secrecy and self-imposed isolation of the industrial firms dominating it. The so-called "triple helix" partnership of industry, universities and government existed even in the heyday of the Object Economy, but it had to undergo several major transformations before assuming its current form of more or less harmonious knowledge networks of mutually respected partners. ${ }^{23}$

The origin of internetworking based knowledge sharing goes back to the 1960s when academic computer scientists pursuing a variety of research projects for ARPA (the U.S. Defense Department's Advanced Research Project Agency, networked their computers to facilitate rapid information exchange and as a result greatly accelerated the R\&D and product development cycles. ${ }^{24}$ The original ARPANET and its successor networks were created by a grass root, bottom up process which developed, in response to immediate need, the basic tools of internetworking: packet switching, TCP/IP software and client server architecture. It also created the fundamental applications for information exchange and retrieval: email, FTP, search engines and eventually the World Wide Web and its multi-media manifestations. Up to the late 1980s the concept and practice of technology and knowledge networking was antithetical to the prevailing culture. Each company, indeed each facility of a given company, was a fortress unto itself. Total secrecy was the mode of operation. The successful company was to keep its products under wrap until their introduction and the details related to them were often not revealed for years after their appearance on the market place. Researchers rarely talked about work in progress; their papers and presentations were well polished and described completed and somewhat obsolete work. Presentations about products described their commercial advantages but remained silent on the technical details. Standards were imposed de facto by the

\footnotetext{
${ }^{23}$ Triple Helix II, http://www.chem.uva.nl/sts/loet/th2/program.htm, Triple Helix Rio 2000, http://www.itoi.ufrj.br/saturday.htm

${ }^{24}$ Barry Leiner et al, A Brief History of the Internet, http://info.isoc.org/internet-history
} 
dominant company in the field or developed at a snail's pace by professional groups under the strong influence of dominant companies. This high level of secrecy necessarily led to tremendous redundancy in effort which amounted to an incredible waste of resources. Every firm had a research laboratory, every facility had a full array of support functions.

Not surprisingly, the Internet was originally shunned by corporate America because it had no provisions for confidentiality and secrecy. The only corporate entities participating in the Internet were the research laboratories of computer and telecommunications equipment manufacturers and telecommunications network operators. Their presence, on the other hand, was opposed and resented by the academics who dominated the net. There was a strong sentiment that the Internet should not be used for any commercial purposes and an elaborate netiquette evolved which frowned on commercial utilization.

The strong Japanese competition of the 1970s and 80s, however, threatened the viability of several major segments of U.S. industry. After losing dominance of the consumer electronics, automobile and semiconductor processing industries, American industry was forced to re-engineer its practices to become more competitive. Firms had to realize that in an increasingly global economy no single firm, no matter how large and powerful, can do it alone. Accepting this axiom lead to inter firm strategic alliances, partnerships, mergers and acquisitions and other forms of cooperation which allowed companies to consolidate and discontinue marginal and duplicate operations, to out-source many functions and share costs of R\&D and product development with corporate allies. ${ }^{25}$ In order for these strategic alliances to be successful, an efficient, rapid method of communications and interactions was needed and the Internet admirably fit the bill. At the same time, the Internet put its indelible mark on the operations of the corporate world. The corporate interest in the net resulted in the development of intranets, encryption based security and firewalls. These security measures not only guard corporate information but are also used to preserve privacy and to protect intellectual property and proprietary information. The emergence of e-commerce has lead to strong corporate participation in the Internet which is intensifying daily. The inherent nature of the Internet allowed the mushrooming of small, highly focused start-up companies which often have vital alliances with large corporation and serve as their source of new ideas. All in all, besides serving as the greatest repository and speediest disseminator of knowledge and information in human history, the Internet is also a great facilitator of business to business and business to consumer interactions and transactions.

Corporate alliance formations also lead to the reconfiguration of the labor market: networked communications made possible the elimination of many middle management functions, and instant data availability catapulted the importance of staff functions such as analysts. Software creation, application development and service

25 John Harbison and Peter Pekar, Smart Alliances, Josee-Bass, 1998

26 Critical Connections: Communication for the Future OTA-CIT-407 
provision became the engine of the new economy and traditional manufacturing has lost ground at least in the developed world. Nearly all job functions required some level of computer literacy. These changes brought about serious and often painful but inevitable and historically not unprecedented structural dislocations in the labor market. ${ }^{26}$

Corporate alliances, partnerships, mergers and acquisitions have been characteristic of the telecom and information industries, especially in the U.S.; the consolidation of the regional Bell Operating Companioes (RBOCs), the proliferation and then consolidation of long distance companies, the consolidation of ISPs, Internet start-up companies and the joining of internet and media companies have been dominating the business scene. The purpose of this process of alliance formation is to ensure greater market share for the surviving firms and to make them more competitive in the market place. The process of corporate alliances is not limited to the US but has a truly global character. Some examples of the cross-border alliances include the AT\&T and BT partnership, the Vodaphone, Vivendi wireless portal alliance and so on. Also in this category are the various international consortia which operate newly privatized and deregulated telephone companies in Latin America, Asia and Eastern Europe.

Alliance forging is not limited to the corporate world. Universities, in alliance with industrial partners and with research sponsoring government organizations, have been strong participants in the information economy. University - Industry interactions go back to the dawn of the industrial revolution. Originally, professors served as consultants and sources of potential employees for industry. Later, firms realized that they needed universities to help them keep abreast of new developments and various industry - university liaison organizations were formed. Starting around the 1960s, larger firms looked upon universities as sources of new ideas and often took advantage of technologies developed at universities under government sponsorship. Many firms also funded research at universities to complement their own in-house efforts. Originally, industrial sponsors were able to dictate at will the terms of these agreements concerning confidentiality and intellectual property ownership. In the U.S. the situation changed drastically in the mid 1970s by which time industry had lesser resources available and universities were thriving due to government and foreign, primarily Japanese, sponsorship. Universities insisted on the right to publish results and on the ownership, or at least co-ownership, of intellectual property. The government was further removed from collaborating with industry; it often acted as an adversarial regulator or as a demanding source of rigid high-maintenance military contracts.

The ever increasing Japanese influence in the technology markets was believed to be due, among other things, to nationally coordinated R\&D efforts such as the Fifth Generation Computer project. It was naturally unthinkable for the US government to follow this example and to pick winners and losers within an industry as this would 
violate the principles and strict peace-time limits on the role of the government under the United States political system. Instead, the US government provided an organized environment for University-Industry interactions. Government funding established a variety of Engineering Research Centers, Science and Technology Centers, Presidential Young Investigators and other mechanisms to attract industry to co-fund research and enter into partnership with university researchers. ${ }^{27}$ The ultimate manifestation of this policy was an industry-university research and later manufacturing organization, Sematech, dedicated to semiconductor processing to combat the Japanese attempts to dominate the field. Similar developments took place in Europe which resulted in a number of ambitious multinational programs such as ACTS, RACE, ESPRIT, and EUREKA. While a plethora of positive results were achieved in these many faceted collaborations no spectacular brake through-s were associated with any of them. The primary reason for the lackluster performance was industry's mistrust of the system. Endless hours were spent to define the role of university partners in such manner that their activities be restricted to so called "precompetitive" research. By the late 1980s industry, as part of its cost cutting and reengineering efforts, largely gave up on basic research. Most fundamental research laboratories were closed down and the firms looked towards universities to satisfy their basic research needs. Yet when it came to specific applications of this research, industry was secretive and non-communicative.

The biotechnology revolution fundamentally altered university-industry interactions. Biotechnology was primarily the result of university based research yet the professors who pioneered it often became entrepreneurs and established their own companies or became top executives or members of the Board of companies utilizing their inventions. University spin-offs were popular before but the allure of biotechnology allowed a professor to spin-off a company of his own and to retain his academic position. This liberal trend continued in connection with the information revolution and its spin-off companies. Today, a close relationship exists between universities and information industry companies which incorporates most of the models of industry-university collaborations experimented with in the past: hiring professorial consultants, hiring students, funding research, participating in joint research projects, participating in industry wide studies and joint ownership of companies.Universities themselves followed the entrepreneurial path and many of them became part owners of start up companies. This became possible because the lion share of entrepreneurial research is funded by venture capital instead of government sponsorship. Also, universities have moved away from their traditional basic research posture and driven by the economic opportunities moved towards more practical and industry relevant research and development such as system engineering, application solutions and marketing and policy issues. The influence of corporate sponsors on university research alarms some because they feel that it derails the true mission of the universities: teaching and pursuing basic research. ${ }^{28}$ Similar misgiving have been voiced concerning university participation in development related Knowledge Networks.

\footnotetext{
${ }^{27}$ NSF

${ }^{28}$ Eyal Press and Jennifer Washburn, The Kept University, The Atlantic Monthly, March 2000
} 
Many of the alliances and partnerships discussed above result in the formation of start-up companies. It is a widely accepted belief that start-up companies function and develop better in a nurturing environment where they are somewhat shielded from daily pressures of the market place. Industrial and Technology Parks and even more so Incubators serve this purpose. In these environments start ups can take advantage of shared infrastructure and facilities and save their resources for their mission critical activities. Originally, incubators were government financed and were located at or near university campuses. Indeed, they represented perhaps the highest level of industry-university-government collaboration. Today, venture capital companies are interested in funding incubators and locating in them the start-ups they finance. This support, nurturing and close supervision improve the chances of their eventual success, which among other things, leads to high return on investment to the venture capitalists.

\section{Knowledge Networks and Development}

We have briefly reviewed the cataclysmic transformations the Information Economy produced in the developed world, particularly in the U.S. but so far we only discussed tangentially the impact of the Information Economy on the developing world. The flexibility and adaptability of the open structure of the Internet makes it possible for it to serve many purposes. It is a network facilitating intense e-commerce competition and Knowledge Networks-based development work simultaneously and equally well. In the development area, the Internet has served as an agent of both widening and narrowing the knowledge gap between rich and poor countries. The crucially important role of Knowledge Networks is to discover, disseminate and apply knowledge in developing countries faster than new knowledge being created in the developed world. On these differences in the rates of knowledge creation and knowledge acquisition may hang the future of economic and political progress in a large part of the world.

The greatest challenge of developing countries is not knowledge discovery but the introduction of this knowledge in a fashion that allows the local population to adopt and utilize it. This concept was articulated and implemented by the Canadian company Acacia which was formed to narrow the digital divide in Africa. Time International quoted a project officer of Acacia: " Our approach is based on the understanding that rural marginalized communities can benefit from technology but only if it is introduced in a comprehensive manner. That means not just dropping computers into communities that may be struggling to feed themselves but ensuring that policies are moving in a direction that will support the sustainability of investment in rural communities." ${ }^{29}$ One of the most important policy direction is the establishment of an educational infrastructure to support sustainable knowledge

29 A Great Leap: Developing Countries are Finding Ways to Leverage Advances in Information

Technology and Help Narrow North South Divide" Time International January 31, 2000 
application. Distance education plays an important role in this area. Satellite based systems can deliver course material even to the most isolated communities. The African Virtual University links twenty four campuses and grants degrees in ICT subjects. The University of South Pacific, main campus in Fiji, provides primarily agricultural information to various Pacific Islands. The Caribbean region also has a similar satellite based education network connecting the various island nations. Increased availability of the Internet allows moving some of the distance learning technology from traditional audio or telephone/satellite based video to, in the first instance, the less cumbersome text-based Internet application which allows a more intimate and in-depth student/instructor relationship via email. As greater bandwidth and processing power becomes available, more sophisticated interactive multimedia educational tools can be used, if appropriate.

One of the welcome attributes of the current development scene is corporate participation. An impressive number of companies, both small and large, are willing to enter into alliances with local companies and take a risk by investing in developing countries. These corporate alliances hardly qualify as Knowledge Networks but they are important in the creation of the Information Economy in developing countries. At this point, the primary focus of the corporate investments is improving telecommunications infrastructure and Internet access. In the telephone infrastructure area most investment is aimed at wireless businesses. Here follow a few examples. One of the most publicized is the Grameen Bank which provides micro-loans to women in remote Bangladesh villages to purchase a solar powered mobile telephone. The women owners are trained in the operation of the instrument. The villagers then may use these phones for a fee to contact relatives or to find out the latest market prices for their produce. ${ }^{30}$ WorldTel, a Canadian venture capital company, made significant investments in wireless local loops in Latin America, Africa and Asia in partnership with local companies. An English company, Millicom International, is a leading provider of prepaid cellular services in partnership with local telephone companies in Asia, the former Soviet Union, Africa and Latin America. These are partnerships of relatively small business firms to improve telecommunications infrastructure and Internet access in the developing world.

A much more ambitious undertaking is contemplated by Africa ONE Ltd. Which in partnership with Lucent Technologies and Global Crossings is proposing to establish a fiber-optic ring around the entire African continent. This undersea ring would be connected at thirty two coastal landing points to the terrestrial networks of telephone companies. The available connectivity and bandwidth will allow direct connection for inter-Africa calls (currently they have to be routed trough the U.S. or Europe) and will also greatly reduce the cost of international calls and Internet connections. ${ }^{31}$ An even larger scale project is being pursued by Teledesic, a company owned in part by Bill Gates and Craig McCaw. ${ }^{32}$ Their aim is to establish world wide broadband access to the Internet using satellite technology. Most Internet sessions, particularly those

30 Banking on the Poor, http://www.rdc.com.au/grameen/home.html

${ }^{31}$ Pat Blake, Telecom by Sea: The Ambitious Africa oNE Project, Global Telephony, May 30, 1998

${ }^{32}$ Bruised Teledesic at Brink, Money, April 11, 2000 
related to knowledge acquisition, are asymmetric; that is to say, most information is flowing from the server to the user. The Teledesic system would therefore use relatively inexpensive satellite downlinks to transport information from the server to the user and avoid the use of more expensive uplinks by utilizing a telephone connection for the transmission of information from the user to the server. In other words, the local phone companies are active participants in this system. The need to use about a dozen low orbit satellites to provide worldwide connectivity has made the construction of this system expensive and it may miss the window created by the current lack of alternative technology to provide general access. Successful penetration by wireless web appliances and increased diffusion of broadband technologies (ISDN, DSL) may preempt the economical use of direct satellite technologies for broadband access before they had a chance to go on-line.

In addition to inter-firm cooperation, companies also form partnerships with organizations from the public and non-profit sector. It was announced recently that the Japanese Internet company, Softbank Inc., in partnership with the World Bank: International Finance Corporation, will invest nearly a half billion dollars in Internet start-up companies in about 100 countries, many of them in the developing world.. The unique combination of Softbank's Internet business capabilities and the World Bank's development related expertise greatly enhances the chances of success of the Internet start-up companies they decide to support. Another private/public partnership is World Space Digital Audio Broadcasting. This technology consists of radio signals beamed through very small aperture terminals (VSAT) to a satellite in geosynchronous orbit and then bounced down to earth ready to be received by digital radio sets. The contents being transmitted consist of audio programming, text to speech conversion and static webpages. The technology will bring digital information to most of the developing world and it is accessible to the rural poor. Some of the capital for the World Space venture was raised from private venture capitalists but some of it was provided by development agencies of the UN and the World Bank.

The original goal of World Space audio broadcasting was the dissemination of AIDS related information in the developing world. This is but one of many telemedicine projects attempting to bring timely medical consultation to some of the most isolated and underdeveloped areas of the world. The rather expensive broadband video linkups used in telemedicine consultations of the developed world are clearly not applicable to jungle hospital situations. HealthNet, a popular medical network in the developing world, uses ham radio equipment to generate and beam signals to a low orbit, store and forward satellite. The satellite beams the signal down to its destination where it is again received and broadcast by ham radio equipment. This relatively inexpensive and somewhat cumbersome set up played an important role in the handling of the Ebola virus crisis. The telemedicine applications illustrate how investment in access creation can readily support the functioning of Knowledge Networks.

The same observation can be made about universal access creation and Knowledge Network establishing activities of the United Nations Development Programme. Its 
focus has been the creation of pilot telecenters which bring the Internet to rural and underserved populations following a "public library" model. There are three demonstration programs for telecenters. The Egypt Technology Access Center ${ }^{33}$ has been concentrating on capacity building through training and skill development in computer literacy. It has created an Internet technology dictionary in Arabic and promoted the creation of Internet content on sustainable development in Arabic. The South African telecenter has so far restricted its activities to policy advice to the Universal Service Agency which has the mandate to establish telecenters countrywide. The telecenter in Odessa, Ukraine is dedicated to provide agricultural information through Internet access to Ukrainian women farmers. The Sustainable Development Program within the UNDP has acted as the first Internet Service Provider in many developing countries (Angola, Chad, Philippines and Honduras). In other countries it worked to establish and enhance connectivity to the Internet. The Internet Initiative for Africa helps 15 Sub-Saharan countries to develop and enhance Internet connectivity and enlarge capacity. The Country Offices of UNDP are pursuing Internet access enhancing projects in over 35 countries around the world ${ }^{34}$ UNDP also established knowledge broker websites on sustainable development for the use of the development community.

UNESCO has established a network of development related university chairs for the exchange of information and knowledge. The most relevant to information technology is ORBICOM, a world wide network of Chairs in communications. There are 165 members from 50 countries, many of them developing nations. The Board of ORBICOM consists of 9 university and 6 corporate representatives. At least some of the research funding is provided by the private sector in the home country of each member. This organization is an excellent model of a properly functioning knowledge network involving many universities from both developed and developing countries and also private sector and government participation.

Non-Governmental Organizations are also instrumental in establishing Knowledge Networks. One example is the International Federation of the Red Cross. This organization consists of representatives from nearly 170 nations. This network has been responsible for setting up systems of disaster management, relevant data bases and an information resource center. The next step will be the establishment of appropriate telecommunications infrastructure which will allow the use of email as the communications of choice among all members. Although Internet connections are becoming more and more available in the developing world, they are usually restricted to large cities. Many disasters occur in remote areas which present difficult communications challenges. One opportunistic solution involves the use of CDROMs with prepackaged information for disaster relief. Other approaches to communicating with remote areas in real time include the use of radio modems and low orbit satellites (LEOs).

\footnotetext{
${ }^{33} \mathrm{http}: / /$ www.tacc.egnet.net/

${ }^{34} \mathrm{http}: / /$ sdnhq.undp.org.htm
} 
Another important NGO Knowledge Network is the Sustainable Development Communications Network (formerly Spinning the Web Network). This network consists of a group of NGOs which are dedicated to using the Internet to meet the goals of sustainable development. Here again contents and access dominate the agenda: develop new tools and contents about sustainable development, build capacity for Internet use, share knowledge. The SDNC is strongly involved in issues related to sustainable environmental developments. Among its member organizations is the Regional Information Center for Central and Eastern Europe which helps solve environmental problems inherited from the Communist economies and seeks to promote sound environmental practices in future undertakings. The Stockholm Environmental Institute is also a member of the network. Its work focuses on policy issues related to links between ecological, social and economic systems at the global and local levels. It has a network encompassing twenty five countries. Access to environmental information, including state of the art research on clean technologies, may be best facilitated via the Internet. The UNEP International Environmental Technology Centre (Osaka, Japan) has an interactive database (http://www.unep.or.jp/) on a full range of environmental technologies and related issues.

\section{Conclusion: The Internet as a Meta-Knowledge Network}

This paper has shown why there is s much hype around the notion of the digital divide and the use of the Internet for local, regional, national, and global socioeconomic development: The promise of information and communication technologies including networking technologies is indeed great. Appropriately used for development of knowledge networks within developing nations and across knowledge communities globally wonderful things may happen for individuals and communities, but it is far from a panacea. The other elements of social and political stability, healthcare, infrastructure development, and education must all come into play. Therefore, knowledge networks are necessary but not sufficient for nations seeking to advance regions and peoples into full participation in the global economy.

Nonetheless, increased access and more affordable connectivity to advanced ICTs and especially wireless and Internet services enhances the ability of development professionals and an increasingly diverse range of citizens of developing countries to access the world's storehouse of information - the Internet. The world may well be enriched as the exchange of information leads in all directions, that is, within communities, regions, and nations; within firms and industries. 